\title{
UTILIZAÇÃO DA DOLOMITA CALCINADA COMO CATALISADOR NA OLIGOMERIZAÇÃO DO GLICEROL
}

\author{
F. J. S. BARROS ${ }^{1}$, F. L. MARQUES ${ }^{1}$, , F. M. T. de LUNA $^{1}$ e R. S. VIEIRA ${ }^{1}$ \\ ${ }^{1}$ Universidade Federal do Ceará, Departamento de Engenharia Química \\ E-mail para contato: fernando_barros17@yahoo.com.br
}

\begin{abstract}
RESUMO - Este trabalho tem como objetivo avaliar o uso da dolomita calcinada como catalisador na reação de oligomerização do glicerol. Inicialmente, o material foi submetido a calcinação por 2 horas a $800^{\circ} \mathrm{C}$. As reações catalisadas pela dolomita calcinada foram conduzidas em Reator Parr, utilizando glicerol P.A, sob fluxo de nitrogênio, aquecimento a $245^{\circ} \mathrm{C}$ e tempo de reação de 6 horas. Para fins comparativos também realizou-se um teste sem a presença do catalisador. Testes reológicos evidenciaram a redução da viscosidade dos produtos obtidos via processo catalítico, em relação aos obtidos sem catalisador e ao glicerol utilizado. A espectroscopia de infravermelho evidenciou a redução dos grupamentos hidroxila e a formação de acroleína e acetonas.
\end{abstract}

\section{INTRODUÇÃO}

O uso de combustíveis alternativos também reforça a necessidade de se encontrar utilizações comerciais para os coprodutos de produção do biodiesel, como a glicerina. Este cenário indica que a viabilização comercial do biodiesel passa pelo consumo deste volume extra de glicerina, buscando aplicações de larga escala e agregando valor à cadeia produtiva (MOTA, 2009).

Hoje no Brasil a produção de glicerol já alcança aproximadamente 250 mil ton/ano. Essa produção excede em muito a demanda e a capacidade de absorção dos mercados atuais, a qual, é principalmente baseada no consumo de glicerol para cosméticos e produtos alimentícios, além da revenda para consumo direto (UMPIERRE; MACHADO 2013).

A glicerina bruta, originada como coproduto da produção do biodiesel, apresenta cerca de $30 \%$ de impurezas em sua composição, como catalisadores, álcoois, ácidos graxos e sais. Estas impurezas dependem da natureza do óleo vegetal ou da gordura animal utilizada e do tipo de catálise empregada na preparação deste biocombustível (LOPES, 2011).

O termo glicerol aplica-se somente ao componente químico puro. O termo glicerina aplica-se aos produtos comerciais purificados, normalmente, contendo pelo menos $95 \%$ 
de glicerol. Vários níveis e designações de glicerina estão disponíveis comercialmente. Eles diferem um pouco em seu conteúdo de glicerol e em outras características, tais como cor, odor e impurezas (KNOTHE et al., 2006).

De acordo com Pagliaro e Rossi (2008), a presença de um grupo OH ligado a cada um dos três átomos de carbono faz do glicerol um potencial candidato para uma grande variedade de reações químicas. A Figura 1 apresenta resumidamente alguns produtos de maior valor agregado resultantes de uma gama variada de reações e processos químicos à base de glicerol.

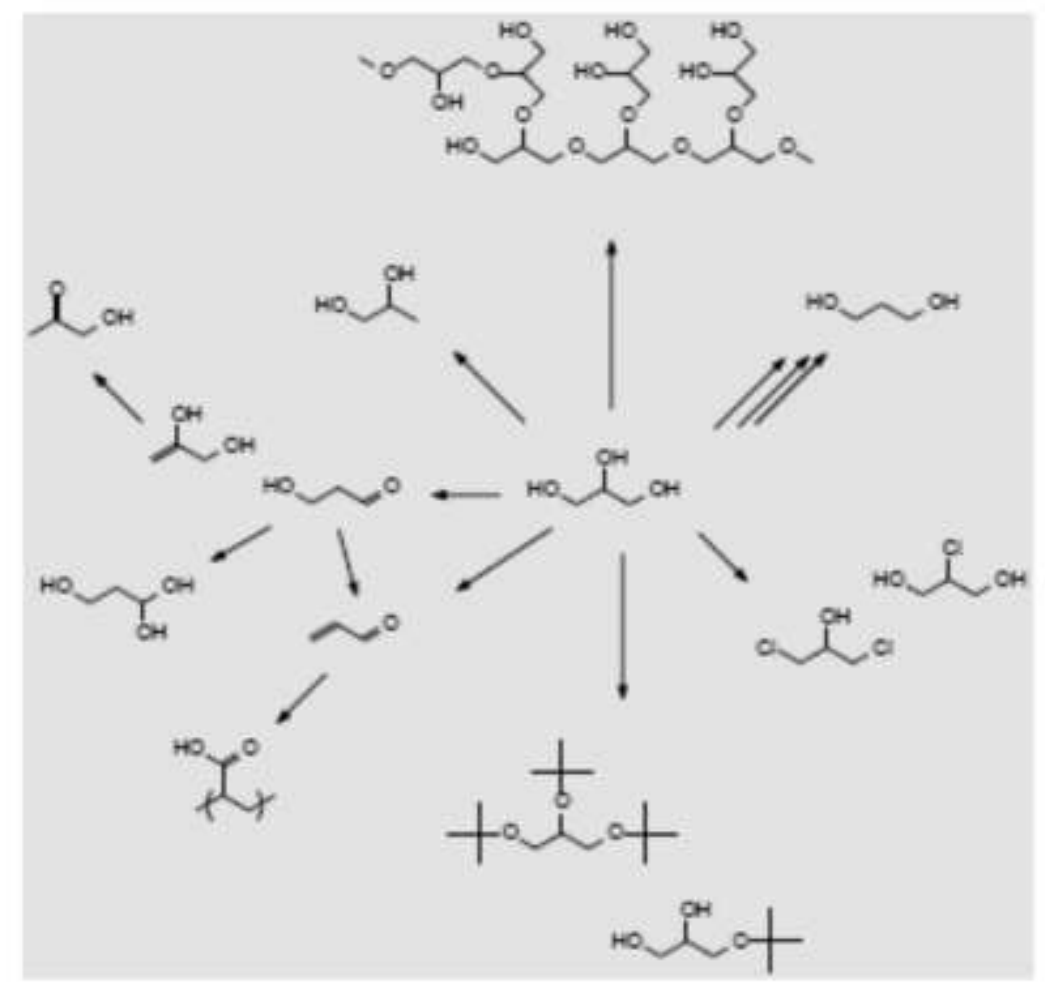

Figura 1 - Produtos da Valorização do Glicerol

Fonte: Umpierre ; Machado (2013)

Dentre os diversos produtos de alto valor agregado passiveis de serem sintetizados a partir do glicerol encontram-se seus oligômeros: diglicerol e triglicerol.

Normalmente utiliza-se catálise homogênea básica para obtenção de éteres de glicerol. A busca por catalisadores heterogêneos com alta atividade e seletividade representa um dos principais desafios. Processos heterogêneos apresentam diversas vantagens como facilidade de separação e reaproveitamento dos sistemas catalíticos; e elevada seletividade (UMPIERRE; MACHADO, 2013)

Este trabalho tem como objetivo avaliar o uso da dolomita como catalisador heterogêneo na oligomerização do glicerol sem a presença de solvente. 


\section{2 .MATERIAL E MÉTODOS}

Utilizaram-se nas reações Glicerol P.A (Vetec), e como catalisadores a dolomita natural e calcinada, adquirida da Itamil Itaoca Minerações. Além disso, foi foi também realizado um teste sem a presença de catalisador. As reações ocorreram em um reator Parr, a $245^{\circ} \mathrm{C}$, com atmosfera inerte provocada pela passagem de nitrogênio, por um período de 6 horas.

\subsection{Ativaçao do Catalisador}

A dolomita foi ativada por calcinação a $800^{\mathrm{a} C}$ por 2 horas em um forno da FDG equipamentos. As amostras foram caracterizadas quanto a distribuição de tamanho de partículas, utilizando um analisador de tamanho de partícula por difração laser Mastersizer 2000 da Malvern Instruments .

\subsection{Viscosidade Intrínseca}

A determinação da viscosidade intrínseca, foi realizada a $40 \pm 0,1^{\circ} \mathrm{C}$, utilizandose um viscosímetro capilar Cannon - Fenske 50, colocado em um banho termostatizado e a partir deste valor, foi calculada a massa molecular média. Pelo método de extrapolação gráfica à diluição infinita, a determinação experimental foi feita pela medição do tempo de escoamento de cinco soluções poliméricas diluídas $(0,01 ; 0,03$, 0,$05 ; 0,07 ; 0,09 \mathrm{~g} / \mathrm{mL}$ ), a partir de uma solução mãe de $0,20 \mathrm{~g} / \mathrm{mL}$ da amostra em água. Os testes foram realizados em duplicata.

Os cálculos da viscosidade específica e reduzida para cada solução e a determinação da viscosidade intrínseca $[\eta]$, foram baseados nas seguintes expressões.

Viscosidade relativa: $\eta_{r e l}=\eta_{s o l} / \eta_{o}=t_{s o l} / t_{o}$

onde $\eta_{\mathrm{o}}$ é a viscosidade do solvente (água ) sem polímero e $\rho_{\mathrm{o}}$ e $\rho_{\text {sol }}$ são as densidades. Nesta relação, assume-se que as densidades da solução e do solvente são iguais, haja visto tratar-se de uma solução extremamente diluída.

Viscosidade específica: $\eta_{s p}=\left(\eta_{s o l}-\eta_{o}\right) / \eta_{o}=\eta_{r e l-1}$

Viscosidade reduzida: $\eta_{r e d}=\eta_{s p} / c$

onde c é a concentração em $\mathrm{g} \mathrm{mL}^{-1}$

Viscosidade intrínseca: $[\eta]=\lim (c \rightarrow 0) \eta_{s p} / c$ 
A relação entre viscosidade intrínseca e massa molar é dada pela correlação de Staudinger-Mark-Houwink apresentada na Equação 5:

$$
[\eta]=K M_{v}{ }^{a}
$$

Em que:

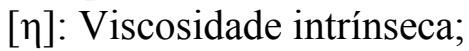

$\mathrm{K}$ : constante referente ao polímero;

a : constante referente ao polímero;

Mv: Massa molecular viscosimétrica.

Na ausência dos parâmetros da correlação de Mark - Houwink - Staudinger, foram utilizados valores para $\mathrm{K}$ a de um polímero que interagisse de forma similar com o mesmo solvente do poliglicerol, neste caso o Poliálcool Vinílico (PVA). Os valores para K e a são respectivamente: $\mathrm{K}=0,0453 \mathrm{~mL} / \mathrm{g}$ e a $=0,64$.

\subsection{Viscosidade Dinâmica}

Para a determinação da viscosidade dinâmica dos diferentes produtos obtidos foi utilizado um viscosímetro da marca Brookfield (Modelo DV-III ULTRA). O instrumento é equipado com cilindros de diâmetros diferentes (spindles), selecionados conforme a viscosidade do fluido. Para os óleos utilizados neste trabalho foi utilizado um cilindro de diâmetro externo de $9,39 \mathrm{~mm}$ e 24,23 $\mathrm{cm}$ de comprimento (Spindle de referência 34).

Para a realização das análises reológicas, foi utilizado, para cada medida, $11 \mathrm{~mL}$ de amostra (de acordo com orientação do fabricante), submetida a estabilização por 15 minutos antes da análise. O equipamento mede a viscosidade de fluidos através da taxa de cisalhamento (Shear Rate). Além do produto da reação, também foi analisado o glicerol utilizado como reagente.

\subsection{Espectroscopia Vibracional na Região do Infravermelho com Transformadas de Fourier (FTIR)}

Para essa análise foi utilizado o equipamento IR-PRESTIGE 21 SHIMADZU FTIR com células de $\mathrm{KBr}$ disponível. A faixa de varredura usada nas análises foi de 400 a $4000 \mathrm{~cm}^{-1}$, com resolução espectral de $8,0 \mathrm{~cm}^{-1}$. Amostras líquidas foram preparadas por disposição de alíquota no próprio suporte de $\mathrm{KBr}$.

\section{RESULTADOS E DISCUSSÃO}

\subsection{Ativação do Catalisador}

Os resultados dos testes de análise de tamanho de particula estao apresentados na tabela 1 . 
Tabela 1 - Análise de tamanho de particula

\begin{tabular}{|l|l|l|l|}
\hline Amostra & uniformidade & $\begin{array}{l}\text { Área } \\
\text { Superficial } \\
\text { Especifica } \\
\left(\mathrm{m}^{2} / \mathrm{g}\right)\end{array}$ & $\begin{array}{l}\text { Diâmetro } \\
\text { médio }(\boldsymbol{\mu m})\end{array}$ \\
\hline $\begin{array}{l}\text { Dolomita } \\
\text { natural }\end{array}$ & $\mathbf{0 , 7 7 3}$ & $\mathbf{1 , 3 7}$ & $\mathbf{1 0 . 2 6 6}$ \\
\hline $\begin{array}{l}\text { Dolomita } \\
\text { calcinada }\end{array}$ & $\mathbf{0 , 7 3 5}$ & $\mathbf{1 , 2 4}$ & 11.07 \\
\hline
\end{tabular}

Os resultados mostraram que a calcinação aumentou ligeiramente o diâmetro médio de partículas do catalisador e reduziu a uniformidade e a área superficial especifica.

\subsection{Viscosidade Intrínseca}

A Figura 1 mostra os gráficos obtidos no teste reológico e utilizados para o cálculo dos valores de viscosidade intrínseca e massa molar média, apresentados na Tabela 2, obtidos pelo método descrito anteriormente para os poligliceróis.

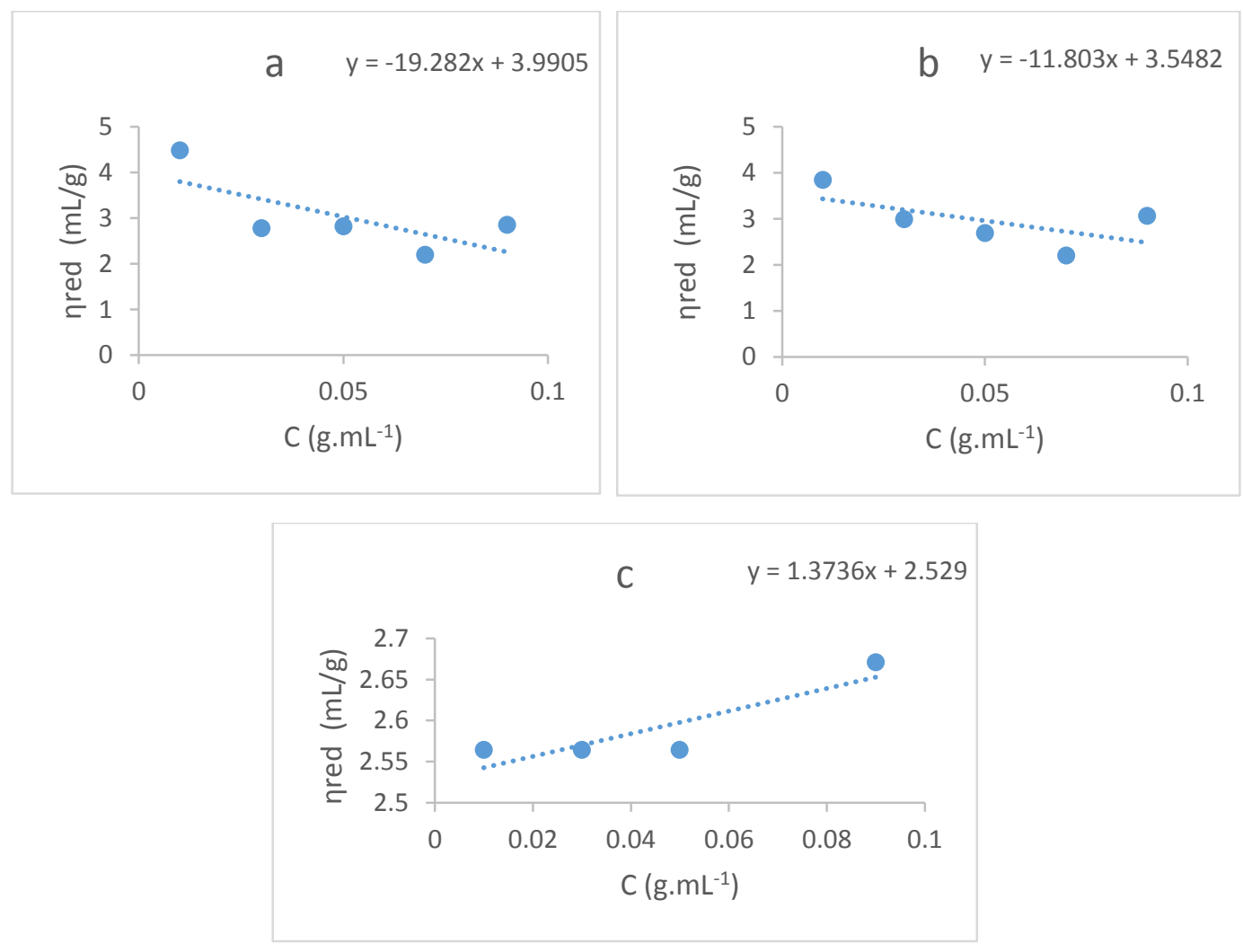

Figura 1 - Curvas Viscosidade Reduzida x Concentração: a) Sem

Catalisador $+6 \mathrm{~h}+245^{\circ} \mathrm{C}$ com fluxo de $\mathrm{N}_{2}$ b) Catalisador pela dolomita $+6 \mathrm{~h}+245^{\circ} \mathrm{C} \mathrm{com}$ fluxo de $\mathrm{N}_{2}$ c) Catalisado pela dolomita calcinada $+6 \mathrm{~h}+245^{\circ} \mathrm{C}$ com fluxo de $\mathrm{N}_{2}$ 
Tabela 2 - Viscosidade Intrínseca e Massa molar média

\begin{tabular}{|c|c|c|c|}
\hline $\begin{array}{c}\text { Catalisador } \\
\text { utilizado }\end{array}$ & $\begin{array}{c}\text { Percentual de } \\
\text { Catalisador }(\%)\end{array}$ & $\begin{array}{c}\text { Viscosidade } \\
\text { Intrinseca }(\mathrm{mL} / \mathrm{g})\end{array}$ & $\begin{array}{c}\text { Massa Molar } \\
\text { Média }\left(\mathrm{g} \cdot \mathrm{mol}^{-1}\right)\end{array}$ \\
\hline Dolomita & 2 & 3.54 & 910,40 \\
\hline Dolomita calcinada & 2 & 2.53 & 536.36 \\
\hline Sem catalisador & - & 3.99 & 1093.83 \\
\hline
\end{tabular}

A calcinação da dolomita não se mostrou efetiva no aumento da oligomerização do glicerol, haja visto que gerou o produto com menor massa molar média. $\mathrm{O}$ produto catalisado pela dolomita apresentou massa molar média cerca de $17 \%$ menor que a do produto sem presença de catalisador, esses resultados revelam serem necessários novos testes afim de verificar se com o aumento do tempo de reação estes comportamentos se repetem.

\subsection{Viscosidade Dinâmica}

A Tabela 3 mostra os resultados obtidos nos ensaios de viscosidade dinâmica.

Tabela 3- Viscosidade Dinâmica dos produtos

\begin{tabular}{|c|c|c|}
\hline Amostra & $\begin{array}{c}\text { Percentual de } \\
\text { Catalisador (\%) }\end{array}$ & $\begin{array}{c}\text { Viscosidade } \\
\text { Dinâmica (cP) }\end{array}$ \\
\hline Glicerol P.A & - & 278.9 \\
\hline $\begin{array}{c}\text { Produto catalisado } \\
\text { pela dolomita }\end{array}$ & 2 & 45.19 \\
\hline $\begin{array}{c}\text { Produto catalisador } \\
\text { pela dolomita } \\
\text { calcinada }\end{array}$ & 2 & 47.59 \\
\hline $\begin{array}{c}\text { Produto sem } \\
\text { catalisador }\end{array}$ & - & 76.18 \\
\hline
\end{tabular}

Percebe-se que houve significativa redução da viscosidade dos produtos em relação ao glicerol utilizado, cerca de 3.6 vezes menor para o produto formado sem uso de catalisador e em torno de 6 vezes paras os obtidos utilzando o catalisador, tanto natural como calcinado. Segundo Mota et al., 2009, a eterificação do glicerol possui a característica de produzir compostos que apresentam menor viscosidade e maior volatilidade, fato que contribui bastante na miscibilidade com outras substâncias.

\subsection{Espectroscopia Vibracional na Região do Infravermelho com Transformadas de Fourier (FTIR)}

A figura 2 apresenta os espectros obtidos via FTIR. 


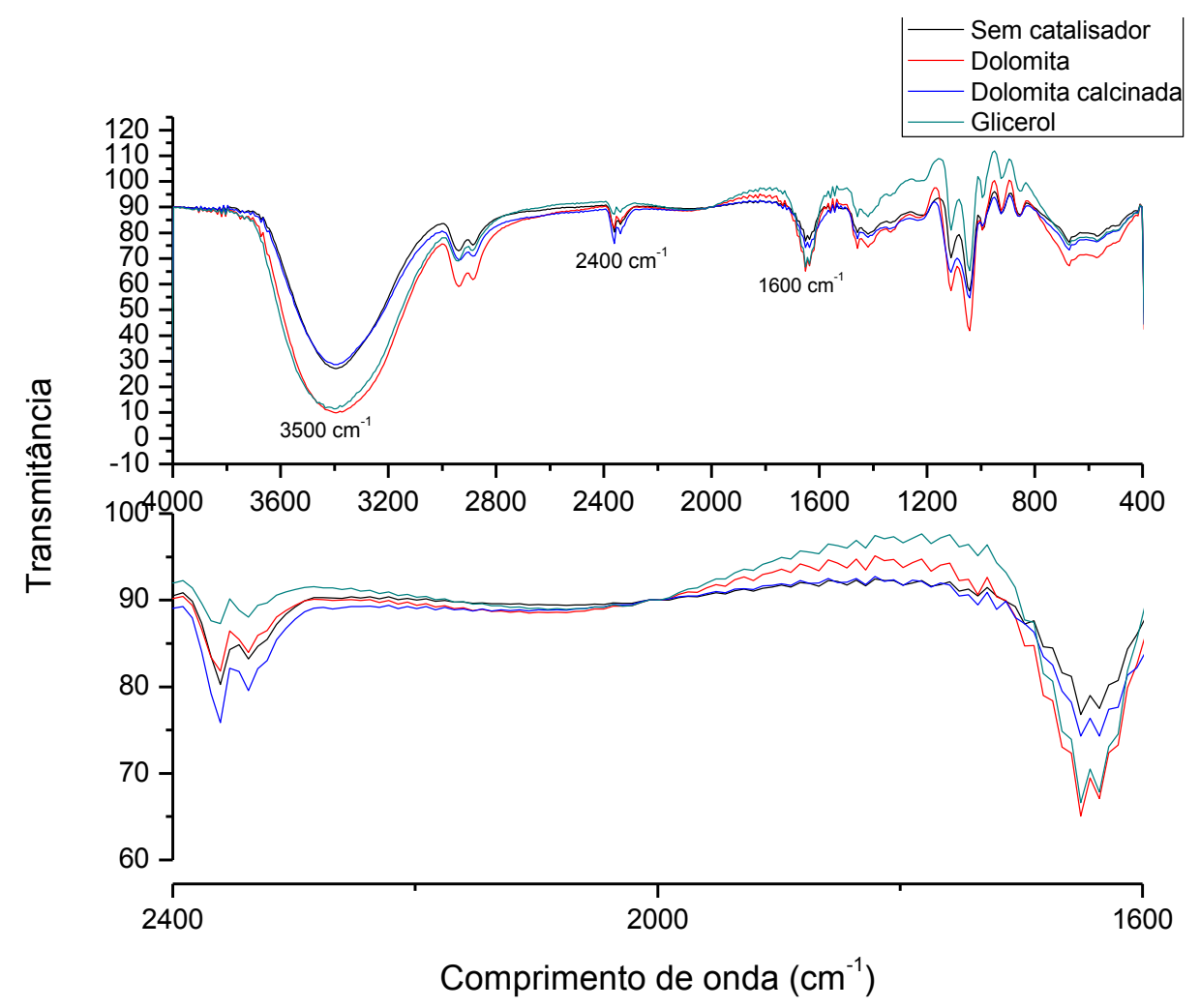

Figura 2 - Espectro infravermelho do glicerol puro, dos produtos obtidos via catalise com a dolomita, dolomita calcinada e sem catalisador.

O espectro de infravermelho dos poligliceróis formados e do glicerol apresentaram uma banda na região de alto número de onda $\left(3500 \mathrm{~cm}_{-1}\right)$ característica da do grupo hidroxila $\mathrm{OH}$. Em todos os testes houve redução da mesma, indicativo da formação dos oligômeros (perda de hidroxila ligada a carbono primário)

A reação catalisada pela dolomita apresentou maior redução desta banda, indicativo de um maior desprendimento das hidroxilas na formação dos oligômeros bem como de outros compostos.

Não foi possível observar a deformação das bandas que representam os álcoois primários e secundários. $\mathrm{O}$ surgimento de uma banda em torno de $1600 \mathrm{~cm}^{-1}$ denota $\mathrm{o}$ aparecimento de moléculas que possuem dupla ligação. $\mathrm{O}$ estiramento $v \mathrm{C}=\mathrm{C}$ neste caso nos confirma a formação de moléculas de acroleína. $2400 \mathrm{~cm}^{-1}$.

$\mathrm{O}$ surgimento de picos nas regiões de acetonas foi observado em $1644 \mathrm{~cm}^{-1} \mathrm{e}$

\section{CONCLUSÃO}

A partir das técnicas utilizadas foi possível verificar a oligomerização do glicerol e quantificar a massa molar dos compostos. O produto obtido via catalise pela dolomita não calcinada atingiu maior grau de polimerização (aproximadamente 10 vezes a massa do glicerol) em relação a dolomita calcinada. Os testes de viscosidade dinâmica apontaram para a diminuição da viscosidade dos poligliceróis em relação ao glicerol, em concordância com a literatura. As análises de infravermelho evidenciaram a redução dos grupamentos hidroxila, e consequentemente a formação de oligômeros, bem como a presença de acroleína e acetonas. 


\section{AGRADECIMENTOS}

À Capes e à Funcap pelas bolsas concedidas.

\section{REFERÊNCIAS}

KNOTHE, G.; GERPEN, J. V.; KRAHL, J.; RAMOS, L. P. Manual do Biodiesel. São Paulo: Editora Blucher, 2006.

LOPES,A.N.; CECHINEL, C.A.;WENTZ, A.P. Coproduto do Biodiesel - Novas Aplicações para Glicerina. Diálogos \& Ciência - Revista da Faculdade de Tecnologia e Ciências - Rede de Ensino. n. 27, 2011.

MOTA, C. J. A; SILVA, C. X. A. da; GONÇALVES, V.L. C; Gliceroquímica: novos produtos e processos a partir da glicerina de produção de biodiesel. Química Nova. v. 32. $\mathrm{n}^{\circ}$ 3. p. 639-648, 2009.

PAGLIARO, M.; ROSSI, M. Future of Glycerol: New Usages for a Versatile Raw Material. Green Chemistry Series. Royal Society of Chemistry, 1st edition, p.104, 2008.

UMPIERRE, A. P.; MACHADO, F. Gliceroquímica e Valorização do Glicerol. Rev. Virtual Quim., p. 106-116. 2013. Disponível em <http://www.uff.br/rvq>. Acesso em 20 de Março de 2014. 